\title{
Exposure of the Hydrophobic Components of Porcine Lung Surfactant to Oxidant Stress Alters Surface Tension Properties
}

\author{
N. Gilliard, * G. P. Heldt, ` J. Loredo," H. Gasser," H. Redl," T. A. Merritt," and R. G. Spragg" \\ ${ }^{*}$ Department of Anesthesiology, University of Lausanne, Lausanne, Switzerland, CH-1011; ${ }^{\ddagger}$ Department of Pediatrics, University of \\ California, San Diego, California 92103; ${ }^{8}$ Department of Medicine, University of California, San Diego, and Veterans Affairs \\ Medical Center, San Diego, California 92161; "Ludwig Boltzman Institute for Experimental and Clinical Traumatology, \\ Vienna, Austria, A-1200; and 'Department of Pediatrics, University of California, Davis, California 95817
}

\begin{abstract}
We have tested the hypothesis that oxidation of lung surfactant results in loss of surface tension lowering function. Porcine lung surfactant was exposed to conditions known to cause lipid peroxidation (0.2 $\mathrm{mM} \mathrm{FeCl}_{2}+0.1 \mathrm{mM} \mathrm{H}_{2} \mathrm{O}_{2}$ or $5 \mu \mathrm{M} \mathrm{CuCl}$ ). Lipid peroxidation was verified by detection of conjugated dienes, thiobarbituric acid reactive substances, fluorescent products, hydroxy alkenals, and loss of unsaturated fatty acids. Exposed samples had significantly diminished surface tension lowering ability in vitro as measured in a bubble surfactometer. Samples exposed to $\mathrm{FeCl}_{2}+\mathrm{H}_{2} \mathrm{O}_{2}$ had significantly diminished surface tension lowering ability in vivo as indicated by their reduced ability to improve lung compliance of surfactant-deficient fetal rabbits. Oxidation of phospholipid mixtures with surface tension lowering activity and containing unsaturated acyl groups resulted in partial loss of activity as determined in vitro. These results suggest that the effect of oxidants on lung surfactant function is due, in part, to effects on the phospholipid components and that acute pulmonary inflammation accompanied by oxygen radical production may result in surfactant lipid peroxidation and loss of surface tension lowering function. (J. Clin. Invest. 1994. 93:2608-2615.) Key words: pulmonary surfactants • phospholipids • dipalmitoylphosphatidylcholine $\bullet$ respiratory distress syndrome, adult • oxidants
\end{abstract}

\section{Introduction}

Acute high-permeability lung injury, often called the adult respiratory distress syndrome (ARDS), ${ }^{1}$ remains a common clinical problem associated with a mortality of $60 \%$. The sequence of pathophysiologic events in the evolution of ARDS is not well understood, although the syndrome has many characteristics of acute inflammation.

In this setting of acute inflammation, data suggest that lung surfactant surface tension lowering ability is decreased. In the

Address correspondence to Roger G. Spragg, M.D., Veterans Affairs Medical Center, 3350 La Jolla Village Drive, San Diego, CA 92161.

Received for publication 8 July 1992 and in revised form 30 December 1993.

1. Abbreviations used in this paper: $\mathrm{A}_{234}$, absorbance at $234 \mathrm{~nm}$; ARDS, adult respiratory distress syndrome; BAL, bronchoalveolar lavage fluid; DAPC, 1,2,-diarachidonoyl phosphatidylcholine; DPPC, 1,2-dipalmitoyl phosphatidylcholine; HNE, 4-hydroxynon-2-enal; HOE, 4-hydroxyoct-2-enal; MDA, malondialdehyde; PL, phospholipid; POPG, 1-palmitoyl-2-oleoyl phosphatidylglycerol; TBARS, thiobarbituric reactive substances.

The Journal of Clinical Investigation, Inc.

Volume 93, June 1994, 2608-2615 healthy lung, surfactant is believed to cause a low surface tension when alveolar surface area is reduced, thus preventing alveolar collapse, loss of lung compliance, and edema formation (1). As loss of compliance, shunt and alveolar edema are hallmarks of ARDS, it has been rational to examine the function of surfactant from patients with acute lung injury. Observations of Ashbaugh et al. (2) on fluid recovered from minced lung tissue obtained postmortem from two patients with ARDS suggested surfactant dysfunction. Hallman (3) demonstrated abnormal phospholipid composition and a profound loss of surface activity of surfactant obtained from ARDS patients. Consistent observations come from studies in which patients with ARDS had lung surfactant phospholipid composition and function significantly different from that of patients with mild respiratory failure or that of normal subjects $(4,5)$. In addition, lung surfactant recovered in bronchoalveolar lavage fluid (BAL) from animal models of acute lung injury demonstrates disturbances of the lung surfactant system $(6,7)$. The relevance of these disturbances to the pathophysiology of acute lung injury is suggested by the therapeutic effect of exogenous surfactant treatment of animals with acute lung injury $(8,9)$. In addition, preliminary reports suggest the possibility of efficacy of surfactant replacement in the setting of $\operatorname{ARDS}(10,11)$.

How might inflammatory events result in alteration of lung surfactant? PMN infiltration of lung tissue occurs early in ARDS $(12,13)$, and the presence of these cells and plasma proteins in BAL of such patients is a prominent finding. In addition, BAL analyses suggest the release of active neutrophil proteases within the inflamed lung (14-16). Although a variety of plasma proteins are capable of inhibiting surfactant surface tension lowering function, surfactant from patients with ARDS that has been separated from hydrophilic substances may have impaired function (17), suggesting a role for additional mechanisms of inactivation. Examination of exhaled breath condensate reveals evidence of hydrogen peroxide $\left(\mathrm{H}_{2} \mathrm{O}_{2}\right)$ and of oxidation of BAL proteins such as $\alpha$-1-proteinase inhibitor $\left(\alpha_{1}-\mathrm{PI}\right)(18,19)$. This oxidation is consistent with the release of reactive oxygen products from stimulated phagocytes (20). Thus, both proteolytic and oxidative injury of lung components may occur during acute lung injury.

Unsaturated fatty acids are substrates for peroxidative attack by reactive oxygen products; aldehydic products of lipid peroxidation with significant chemotactic or cytotoxic activity may result (21). Lung surfactant is $~ 90 \%$ lipid [ of which $90 \%$ is phospholipid (PL)] and $10 \%$ surfactant-associated proteins. However, a minority of lung surfactant phospholipid acyl sidechains are unsaturated, and therefore it is necessary to determine whether lipid peroxidation will have a substantive effect on surfactant function. To understand better the susceptability of lung surfactant to lipid peroxidation and the resultant effect 
on surface tension lowering ability, the hydrophobic components of porcine lung surfactant were exposed to oxidizing conditions, and the chemical and functional consequences were determined. Results of these experiments suggest that relatively minor alterations in lung surfactant structure caused by lipid peroxidation result in significant alterations in surface tension lowering function.

\section{Methods}

\section{Surfactant preparation}

Pulmonary surfactant was obtained by lavaging lungs of live pigs with 3 liters of cold $150 \mathrm{mM} \mathrm{NaCl}$ containing EDTA $(1 \mathrm{~g} /$ liter $)$ and butylated hydroxytoluene (BHT, $4.4 \mathrm{mg} /$ liter ). The lavage fluid was retrieved on ice and immediately centrifuged at $400 \mathrm{~g}$ for $15 \mathrm{~min}$ at $4^{\circ} \mathrm{C}$ to remove cells and debris. The supernatant was centrifuged at $10,000 \mathrm{~g}$ for 90 min at $4^{\circ} \mathrm{C}$, and the pelleted surfactant was resuspended in a few milliliters of supernatant fluid and stored under $\mathrm{N}_{2}$ at $-70^{\circ} \mathrm{C}$. Before analytic determinations, lipids were extracted using the method described by Bligh and Dyer (22). After evaporation of the organic solvent under $\mathrm{N}_{2}$, dry lipids were resuspended at a PL concentration of $25 \mathrm{mg} / \mathrm{ml}$ in the appropriate solvent $\left(\mathrm{H}_{2} \mathrm{O}\right.$ or $\left.50 \mathrm{mM} \mathrm{NaCl}\right)$ by agitation for $30 \mathrm{~min}$ (Big Vortexer; Glas-Col Apparatus Co., Terre Haute, IN) and sonication on ice (20-s bursts every $30 \mathrm{~s}$ for $5 \mathrm{~min}$ ) using a Microson (Heat Systems-Ultrasonics Inc., Farmingdale, NY) set at $23 \mathrm{kHz}, 25 \mathrm{~W}$. PL concentration was calculated from phosphorous content (23).

\section{Exposure of surfactant to oxidant generating systems}

Extracted pig surfactant was exposed in vitro to two different oxidant conditions: $\mathrm{CuCl}_{2}$ or $\mathrm{FeCl}_{2} / \mathrm{H}_{2} \mathrm{O}_{2}$. Exposure to metal ions has been shown to result in oxidation of low density lipoproteins or liposomes $(24,25)$. Chemical mechanisms are complex; in the case of iron-mediated oxidation, a Fe${ }^{2+}: \mathrm{Fe}^{3+}$ complex acting independent of $\mathrm{HO}$ may initiate lipid peroxidation (25). For exposure of surfactant to $\mathrm{CuCl}_{2}$, extracted pig surfactant was diluted to a concentration of $1 \mathrm{mg} \mathrm{PL} / \mathrm{ml}$ in $\mathrm{H}_{2} \mathrm{O}$, since in $\mathrm{H}_{2} \mathrm{O}$, surfactant makes a clear, stable, homogeneous suspension, whereas in $150 \mathrm{mM} \mathrm{NaCl}$ the suspension is more turbid, and surfactant precipitates over time. Oxidation was initiated at room temperature by the addition of a freshly prepared aqueous $\mathrm{CuCl}_{2}$ solution ( final concentration $5 \mu \mathrm{M}$ ). Samples were incubated at 37 or $24^{\circ} \mathrm{C}$ for up to $24 \mathrm{~h}$. For exposure of surfactant to $\mathrm{FeCl}_{2} / \mathrm{H}_{2} \mathrm{O} 2$, extracted pulmonary surfactant was diluted at a concentration of $1 \mathrm{mg} \mathrm{PL} / \mathrm{ml}$ in $50 \mathrm{mM} \mathrm{NaCl}$ ( $\mathrm{pH} \mathrm{7.0)}$. $\mathrm{FeCl}_{2}$ was added $(0.2 \mathrm{mM}$ final concentration). Peroxidation was initiated by addition of $\mathrm{H}_{2} \mathrm{O}_{2}(0.1 \mathrm{mM}$ final concentration) (25). Control samples lacking surfactant, $\mathrm{FeCl}_{2}$, or $\mathrm{H}_{2} \mathrm{O}_{2}$ were also prepared. Samples and controls were incubated at $37^{\circ} \mathrm{C}$.

To investigate the causal relationship between lipid peroxidation and loss of surfactant biophysical function, protein-free surfactants were exposed to oxidizing conditions to discover if phospholipid peroxidation alone might alter biophysical properties. Either $(a)$ a mixture of 1,2-dipalmitoyl phosphatidylcholine (DPPC), 1-palmitoyl-2-oleoyl phosphatidylglycerol (POPG), and palmitic acid (3:1:0.6 wt/wt/wt in $50 \mathrm{mM} \mathrm{NaCl}$ ) with or without $2 \%$ (by weight) 1,2-diarachidonoyl phosphatidylcholine (DAPC), or (b) Exosurf (DPPC, tyloxapol, hexadecanol, by weight $13.5: 1.5: 1$ ) was oxidized by exposure to $0.2 \mathrm{mM}$ $\mathrm{FeCl}_{2}+0.1 \mathrm{mM} \mathrm{H}_{2} \mathrm{O}_{2}$ as described. To detect the generation of nonsedimentable inhibitors of function and to control for the effects of sedimentation, surfactants exposed to oxidizing conditions were either analyzed directly or pelleted $(10,000 \mathrm{~g}$ for $60 \mathrm{~min})$ and resuspended in supernatant or buffer. Unoxidized DPPC/POPG/PA/DAPC was resuspended in the supernatant of oxidized DPPC/POPG/PA/DAPC. Exosurf was adjusted to $0.125 \mathrm{mg} \mathrm{PL} / \mathrm{ml}$, as this concentration affords optimal surface tension lowering activity in the bubble surfactometer. Other samples were adjusted to $1 \mathrm{mg} \mathrm{PL} / \mathrm{ml}, 150 \mathrm{mM} \mathrm{NaCl}, 5 \mathrm{mM}$ $\mathrm{CaCl}_{2}, 5 \mathrm{mM}$ Tris, $\mathrm{pH}$ 7.0-7.4, before using the pulsating bubble sur- factometer to determine minimum surface tension lowering activity after 10 min of pulsation.

\section{Lipid analyses}

Conjugated dienes. For samples exposed to $\mathrm{CuCl}_{2}$, absorbance at 234 $\mathrm{nm}\left(\mathrm{A}_{234}\right)$ was monitored continuously or the ultraviolet (UV) spectrum was recorded every $2 \mathrm{~h}$ for up to $62 \mathrm{~h}$ (Uvikon 810; Tegimenta AG, Rotkreutz, Switzerland) to provide a qualitative assessment of conjugated diene formation. Values were compared with those obtained from a control containing the same amount of surfactant but no $\mathrm{CuCl}_{2}$. Incubation of $\mathrm{CuCl}_{2}$ alone produced no change in $\mathrm{A}_{234}$. For quantitative measurements, $0.5 \mathrm{ml}$ of the sample was mixed with $7 \mathrm{ml}$ of a 2:1 ( vol $/ \mathrm{vol})$ mixture of chloroform $/$ methanol preheated to $45^{\circ} \mathrm{C}$. The mixture was mixed vigorously (vortex mixer) for $30 \mathrm{~s}$, and $2 \mathrm{ml}$ of distilled water acidified with $0.1 \mathrm{~N} \mathrm{HCl}$ to a $\mathrm{pH}$ of 2.5 was added. After mixing (vortex mixer) for $30 \mathrm{~s}$, the mixture was centrifuged at $1,500 \mathrm{~g}$ for $10 \mathrm{~min}$, and $4.5 \mathrm{ml}$ of the lower layer was transferred to a glass tube, and the chloroform was evaporated under a stream of $\mathrm{N}_{2}$. The residue was reconstituted with $0.5 \mathrm{ml}$ of $n$-heptane, the absorbance at $234 \mathrm{~nm}$ was measured, and the relative concentration of conjugated dienes was calculated assuming $\epsilon_{234}: 29,500 \mathrm{~cm}^{-1} \mathrm{M}^{-1}(24,26)$.

Thiobarbituric reactive substances (TBARS). Of the sample to be analyzed, $0.5 \mathrm{ml}$ was added to $1 \mathrm{ml}$ of a 1:1:1 ( $\mathrm{vol} / \mathrm{vol} / \mathrm{vol})$ solution of $15 \%$ (wt/vol) TCA, $0.375 \%$ (wt/vol) thiobarbituric acid, 0.25 N hydrochloric acid, and $0.01 \%$ (wt/vol) butylated hydroxytoluene. The mixture was heated at $95^{\circ} \mathrm{C}$ for $25 \mathrm{~min}$. The supernatant was obtained by centrifugation at $1,500 \mathrm{~g}$ for $5 \mathrm{~min}$, and the absorbance at $535 \mathrm{~nm}$ was measured. Standard calibration was achieved using malondialdehyde (MDA) freshly prepared by acid hydrolysis of malonaldehyde bis dimethylacetal.

Fluorescent products. Samples were reextracted, and fluorescent products were measured as the relative fluorescence intensity at an excitation wavelength of $360 \mathrm{~nm}$ and an emission wavelength of 420 nm (27).

Fatty acid composition. Samples were reextracted under $\mathrm{N}_{2} .2 \mathrm{ml}$ surfactant lipids was mixed with $4 \mathrm{ml}$ chloroform:methanol (2:1, vol/ vol). After centrifugation $\left(4,500 \mathrm{~g}, 10 \mathrm{~min}\right.$ at $\left.4^{\circ} \mathrm{C}\right)$, the lower phase was washed with $2 \mathrm{ml} \mathrm{MeOH} / 150 \mathrm{mM} \mathrm{NaCl}(1: 1, \mathrm{vol} / \mathrm{vol})$ and then with $2 \mathrm{ml} 150 \mathrm{mM} \mathrm{NaCl}$. Fatty acid methyl ester (FAME) composition was then determined by gas-liquid chromatography with flame ionization detection (GLC-FID). After evaporation of $100 \mu$ lipid extract, the FAMEs were generated by treatment of the residue with sodium methoxide in methanol at $60^{\circ} \mathrm{C}$. The solution was extracted twice with $n$-hexane and analyzed by GLC-FID using a gas chromatograph (model 3800; Dani, Monza, Italy) fitted with a $12 \mathrm{~m} \times 0.22 \mathrm{~mm}$ id fused silica capillary column ( model BP-20; Marchery \& Nagel, Düren, Germany) using hydrogen as the carrier gas. The flame ionization detector and the injection port temperature were maintained at $250^{\circ} \mathrm{C}$; the column temperature was maintained at $150^{\circ} \mathrm{C}$ for $3 \mathrm{~min}$ and then increased to $230^{\circ} \mathrm{C}$ at $5^{\circ} \mathrm{C} / \mathrm{min}$. Averages of at least two separate analyses per sample are presented. Measurement variability within samples was $<3 \%$ and between duplicates was $\leq 10 \%$.

Hydroxy alkenal content. Hydroxy alkenals were determined as 2,4-dinitrophenyl hydrazone (DNPH) derivatives by HPLC (28). Samples of $0.5 \mathrm{ml}$ were incubated with $0.5 \mathrm{ml}$ 2,4-dinitrophenylhydrazine solution $(0.5 \mathrm{mg} / \mathrm{ml} 1 \mathrm{~N} \mathrm{HCl})$ for $2 \mathrm{~h}$ at $24^{\circ} \mathrm{C}$. The reaction mixture was extracted three times with $0.6 \mathrm{ml}$ dichloromethane. The combined organic phases were concentrated and preseparated by TLC ( silica gel 60; E. Merck, Darmstadt, Germany) using dichloromethane as the developing solvent. The separated hydroxy alkenal-DNPH derivatives were eluted from the silica gel three times with methanol. Finally, 4-hydroxynon-2-enal (HNE) and 4-hydroxyoct-2-enal (HOE) hydrazones were separated by HPLC on a Spherisorb ODS $2.5 \mu \mathrm{m}, 4 \times 250 \mathrm{~mm}$ column using acetonitrile $/ \mathrm{H}_{2} \mathrm{O}(60: 40$, vol/vol $)$ as the mobile phase and a detection wavelength of $365 \mathrm{~nm}$. Authentic standard derivatives were used for peak identification and quantification. Measurement variability within samples was $<3 \%$ and between duplicates was $\leq 12 \%$. 


\section{Detection of antioxidant capacity}

$\alpha$-Tocopherol. $\alpha$-Tocopherol content was determined after first reextracting the samples using the procedure of Biesalski et al. (29). HPLC separation was achieved with a Nucleosil $\mathrm{NH}_{2}, 5 \mu \mathrm{m}, 4 \times 250 \mathrm{~mm}$ column. The mobile phase of $n$-hexane/2-propanol (96:4, vol/vol) provided isocratic elution at a flow rate of $1.1 \mathrm{ml} / \mathrm{min}$. Absorbance was monitored at $295 \mathrm{~nm}$. D,L tocopherol was used as an internal standard. Measurements had a coefficient of variation of $2.2 \%$ as determined from six measurements from a serum pool.

Reactive sulfhydryl groups. Total reactive sulfhydryl groups were determined using 5,5'-dithio-bis-2-nitrobenzoic acid reagent according to published methods ( 30$)$

\section{Surfactant surface activity}

In vitro function. Because surfactant PLs express no surface tension lowering activity when suspended in distilled water, before in vitro assays, we restored an $\mathrm{NaCl}$ concentration of $150 \mathrm{mM}$ to samples suspended in $\mathrm{H}_{2} \mathrm{O}$ by adding $50 \mu \mathrm{l}$ of a $3 \mathrm{M} \mathrm{NaCl}$ solution $(\times 20)$ per $\mathrm{ml}$ of sample. By doing so, PL were diluted to $0.95 \mathrm{mg} / \mathrm{ml} 150 \mathrm{mM} \mathrm{NaCl}$. All samples and controls were assayed blindly at a concentration of 0.95 or $1 \mathrm{mg} \mathrm{PL} / \mathrm{ml}$ in a pulsating bubble surfactometer at $37^{\circ} \mathrm{C}(31) .10 \mathrm{~s}$ after the bubble was formed, it was pulsated at a rate of 20 cycles per minute between minimum and maximum diameters of 0.4 and 0.55 $\mathrm{mm}$, respectively. The surface tension at the minimum size bubble was recorded for each cycle and recorded on a microcomputer. Subsequently, the area under the surface tension-time plot was determined and used for statistical analyses.

In vivo function. To measure the surface activity in an in vivo model, surfactant was concentrated by centrifugation $(10,000 \mathrm{~g}, 90$ $\min , 4^{\circ} \mathrm{C}$ ) to a PL concentration of $20 \mathrm{mg} / \mathrm{ml}$ in $150 \mathrm{mM} \mathrm{NaCl}$. Measurements of copper in the supernatants indicated that $\geq 90 \%$ of copper coprecipitated with the surfactant. Therefore, to prepare nonoxidized control samples containing a concentration of copper equivalent to that contained in the oxidized samples, samples were concentrated by lyophylization and subsequently resuspended in $150 \mathrm{mM} \mathrm{NaCl}$. Control samples were resuspended in $150 \mathrm{mM} \mathrm{NaCl} / 5 \mu \mathrm{M} \mathrm{CuCl}_{2}$ just before assay of in vivo function.

New Zealand rabbit does of 27-d gestation were anesthetized intravenously with pentobarbital and delivered of fetuses by Cesarean section. The fetuses were anesthetized, paralyzed, weighed, and maintained in a thermoneutral environment while the trachea was cannulated with an 18-gauge catheter secured by a ligature. Surfactant $(2 \mathrm{mg}$ in $0.15 \mathrm{ml} 150 \mathrm{mM} \mathrm{NaCl}$ ) was introduced via the catheter and followed by $0.3 \mathrm{ml}$ of air and $0.15 \mathrm{ml}$ saline. The animals were then placed in a thermostatted flow plethysmograph, and the tracheostomy tubes were attached in parallel to a modified Baby Bird ventilator (Bird Products Corp., Palm Springs, CA). They were ventilated with 30 breaths per minute, $\mathrm{I}: \mathrm{E}=1: 4$, peak inspiratory pressure of $25 \mathrm{~cm} \mathrm{H}_{2} \mathrm{O}$, and positive end-expiratory pressure of $0 \mathrm{~cm} \mathrm{H}_{2} \mathrm{O}$. Dynamic compliance was determined every $10 \mathrm{~min}$ for $60 \mathrm{~min}$. The area under the compliance-time plot was used for subsequent statistical analyses.

\section{Statistics}

Data are presented as mean \pm SD unless otherwise noted. Differences between groups were detected either by one- or two-way ANOVA with Bonferroni post hoc test for pairwise comparison between groups. Differences were considered significant when the probability of a type I error was $<0.05$.

\section{Results}

Lipid peroxidation. Exposure of porcine surfactant to oxidizing conditions resulted in findings consistent with formation of conjugated dienes and TBARS.

Measurement of conjugated diene concentration after $2 \mathrm{~h}$ of exposure of surfactant $(1 \mathrm{mg} / \mathrm{ml})$ to $0.2 \mathrm{mM} \mathrm{FeCl}_{2}+0.1$
mM H $\mathrm{H}_{2} \mathrm{O}_{2}$, after $24 \mathrm{~h}$ of exposure to $5 \mu \mathrm{M} \mathrm{CuCl}_{2}$, or after no exposure indicated the presence of $31.89 \pm 3.69,24.21 \pm 4.80$, and $9.65 \pm 7.11 \mathrm{nmol}$ conjugated dienes (CD), respectively $(n$ $=3$, each group). These results indicate a net production of up to $\sim 22 \mathrm{nmol} \mathrm{CD} / \mathrm{mg}$ surfactant. Experiments to describe qualitatively the formation of conjugated dienes during exposure to $\mathrm{FeCl}_{2}+\mathrm{H}_{2} \mathrm{O}_{2}$ were frustrated by marked signal variability. However, exposure of surfactant to $\mathrm{CuCl}_{2}$ could be performed in nonsedimenting suspensions with continuous spectrophotometry. When surfactant $(1 \mathrm{mg} / \mathrm{ml})$ was exposed to $5 \mu \mathrm{M}$ $\mathrm{CuCl}_{2}$ at $24^{\circ} \mathrm{C}$, monitoring of $\mathrm{A}_{234}$ showed an increase in absorbance that commenced immediately and reached a maximum after $20 \mathrm{~h} . \mathrm{A}_{234}$ stabilized between 20 and $34 \mathrm{~h}$ and decreased thereafter (Fig. $1 A$ ). $\mathrm{A}_{234}$ of surfactant alone decreased slightly
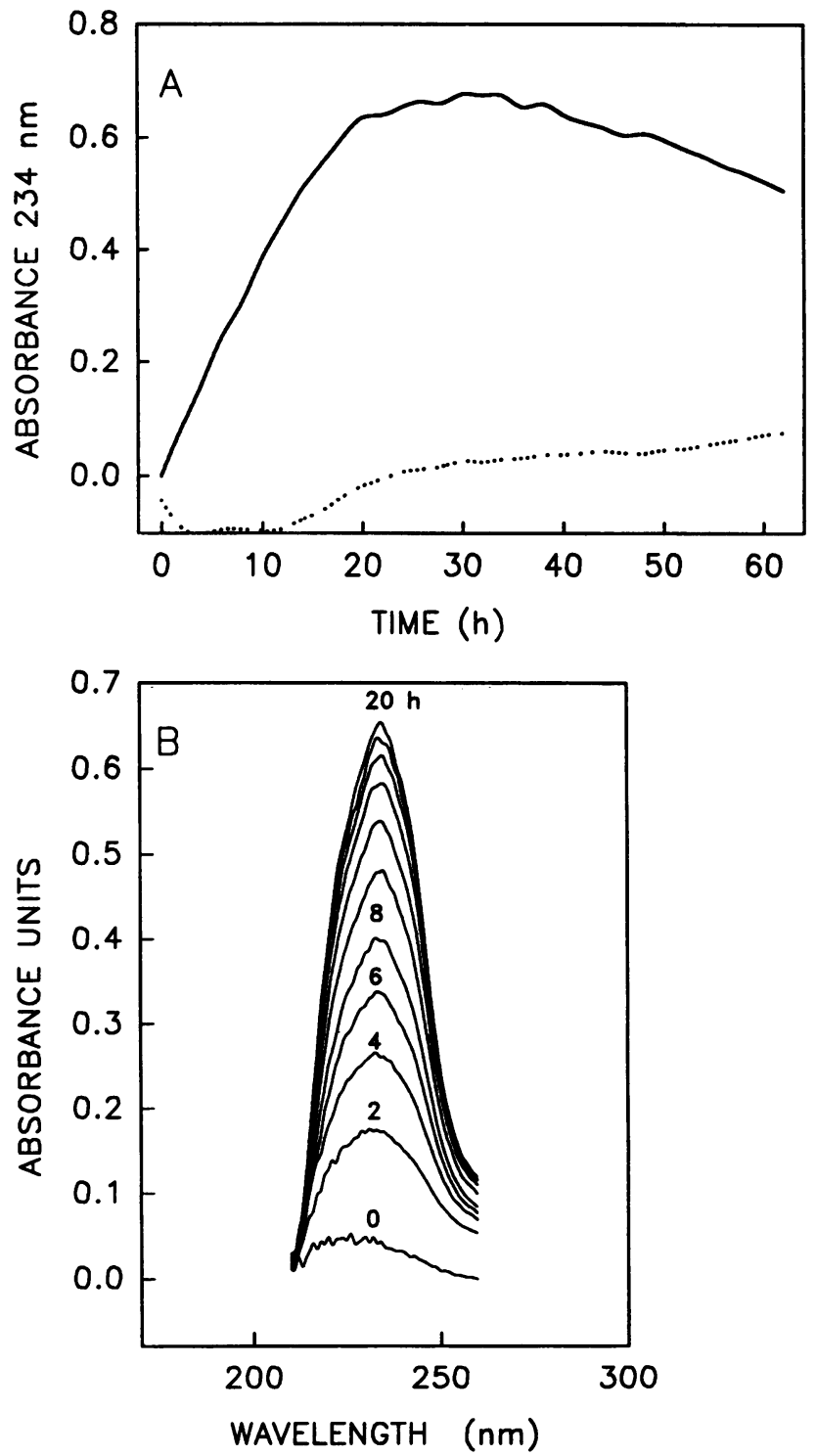

Figure 1. $(A)$ The formation of conjugated dienes, as evidenced by increased $A_{234}$, during exposure of surfactant $(1 \mathrm{mg} / \mathrm{ml})$ to $5 \mu \mathrm{M}$ $\mathrm{CuCl}_{2}(-)$ indicates no lag period and peak formation after $\sim 30$ h. Unexposed surfactant ( $\cdots \cdots)$ ) showed minimal evidence of conjugated diene formation. $(B)$ Difference spectra acquired at 2-h intervals of surfactant $\left(1 \mathrm{mg} / \mathrm{ml}\right.$ ) exposed to $5 \mu \mathrm{M} \mathrm{CuCl}_{2}$ vs unexposed surfactant indicate formation of a discrete peak at $234 \mathrm{~nm}$ consistent with formation of conjugated dienes. 


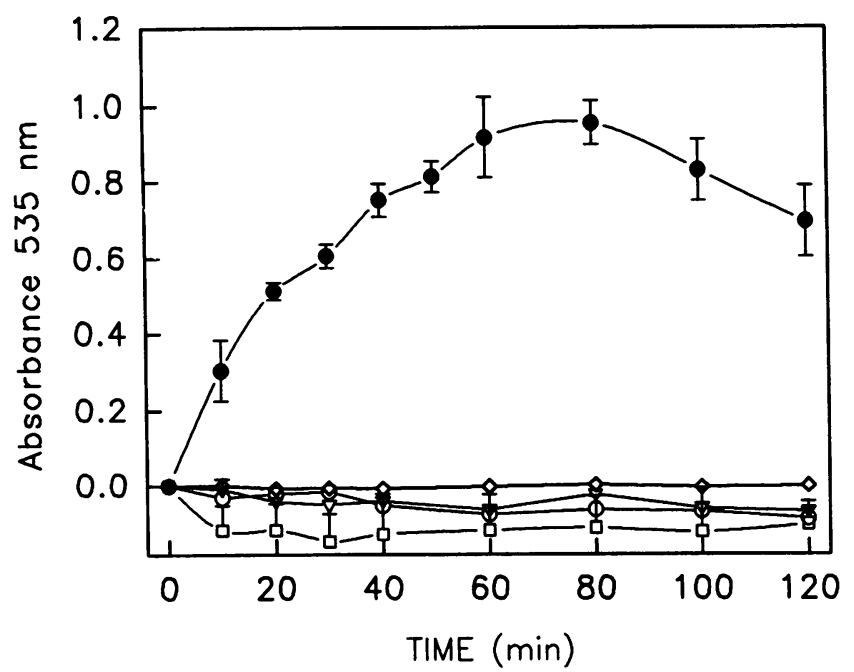

Figure 2. Formation of TBARS, as indicated by $\mathrm{A}_{535}$, from surfactant $(1 \mathrm{mg} / \mathrm{ml})$ exposed to $\mathrm{FeCl}_{2}(0.2 \mathrm{mM})+\mathrm{H}_{2} \mathrm{O}_{2}(0.1 \mathrm{mM})(\bullet) ; \mathrm{FeCl}_{2}$ only (O); $\mathrm{H}_{2} \mathrm{O}_{2}$ only $(\nabla)$; or unexposed ( $\left.\square\right) ; \mathrm{FeCl}_{2}+\mathrm{H}_{2} \mathrm{O}_{2}$ without surfactant $(\diamond)$. Only when the complete oxidizing system is present is evidence of TBARS formation found.

during the first $2 \mathrm{~h}$, remained stable during the next $10 \mathrm{~h}$, and then increased slightly. $\mathrm{A}_{234}$ of $5 \mu \mathrm{M} \mathrm{CuCl}_{2}$ did not vary during $60 \mathrm{~h}$, and results of exposing surfactant to $\mathrm{Cu}^{2+}$ at 24 and $37^{\circ} \mathrm{C}$ were qualitatively similar (data not shown). The change of the UV spectrum over time and the progressive appearance of a peak at $234 \mathrm{~nm}$ are shown in Fig. $1 B$. As the absence of a lag phase after addition of $\mathrm{CuCl}_{2}$ and before detection of conjugated diene formation contrasted with results from oxidation of low density lipoprotein (24), we measured levels of $\alpha$-tocopherol and of free sulfhydryl groups in oxidized and control surfactant samples. Neither $\alpha$-tocopherol nor free sulfhydryl groups could be detected in any samples, consistent with the absence of apparent functional antioxidant activity.

To determine if fatty acid peroxidative changes progressed to formation of aldehydic products, we sought presence of TBARS, as well as HNE, and HOE, bioactive products of lipid peroxidation. Measurement of TBARS in samples exposed to $\mathrm{FeCl}_{2} / \mathrm{H}_{2} \mathrm{O}_{2}, \mathrm{CuCl}_{2}$, or unexposed indicated the presence of $8.54 \pm 2.08,4.67 \pm 0.33$, and $1.33 \pm 1.32 \mathrm{nmol}$ TBARS/mg surfactant, respectively ( $n=3$, each group). The formation of TBARS during exposure of surfactant to $\mathrm{FeCl}_{2} / \mathrm{H}_{2} \mathrm{O}_{2}$ or to each component is shown in Fig. 2. TBARS were produced only in the sample containing the complete oxidizing system; there was no change in $\mathrm{A}_{535}$ in the control sample containing surfactant only or in samples containing either $\mathrm{H}_{2} \mathrm{O}_{2}$ or $\mathrm{FeCl}_{2}$ in the absence of surfactant. A significant increase in concen-

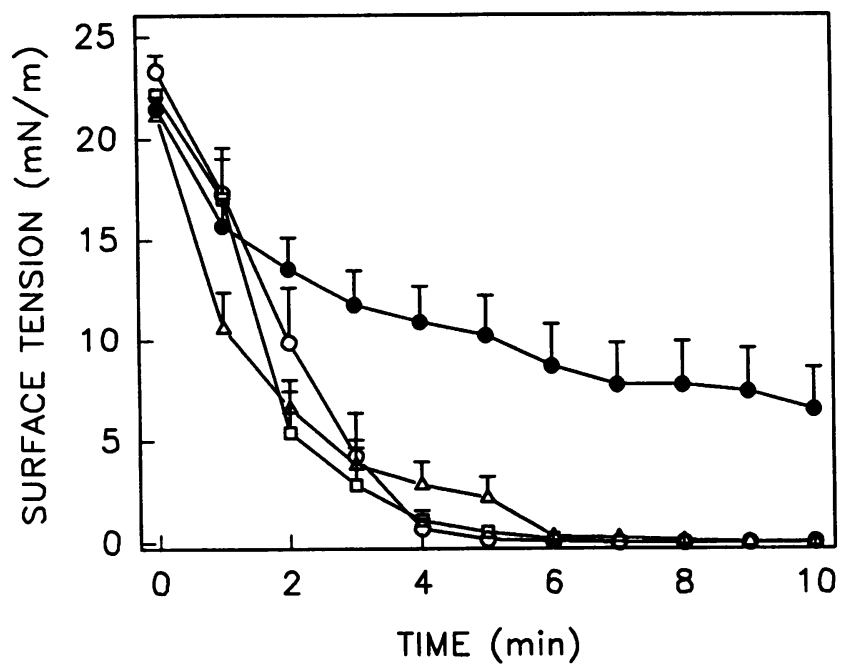

Figure 3. Bubble surfactometer surface tension measurements at minimum bubble size indicate significant inhibition of function of surfactant exposed to $\mathrm{FeCl}_{2}+\mathrm{H}_{2} \mathrm{O}_{2}$ (conditions as for Fig. 2) (•) as compared with surfactant exposed to $\mathrm{FeCl}_{2}$ only $(0), \mathrm{H}_{2} \mathrm{O}_{2}$ only $(\Delta)$, or unexposed $(\square),(n=12$, each condition; mean \pm SEM; $P<0.0001)$.

tration of hydroxyalkenals was detected. Samples exposed as described to $\mathrm{FeCl}_{2}+\mathrm{H}_{2} \mathrm{O}_{2}$, to $\mathrm{CuCl}_{2}$, or unexposed contained $3.02 \pm 0.69,2.12 \pm 0.15$, or $0.12 \pm 0.01 \mathrm{nmol} \mathrm{HNE} / \mathrm{mg} \mathrm{PL}$ and $1.27 \pm 0.20,0.83 \pm 0.02$, and $0.06 \pm 0.02 \mathrm{nmol} \mathrm{HOE} / \mathrm{mg} \mathrm{PL}$, respectively $(n=3)$.

Formation of peroxidative products from di- or polyunsaturated phospholipid acyl groups should be accompanied by a decrease in the fractional content of unsaturated fatty acids derived from oxidized surfactant phospholipids. Results of analysis of fatty acid composition are shown in Table I and indicate an apparent difference in $18 / 2$ and $20 / 4$ fatty acid composition of oxidized as contrasted to control surfactant samples.

Samples exposed to $\mathrm{Fe}^{2+} / \mathrm{H}_{2} \mathrm{O}_{2}$ or $\mathrm{Cu}^{2+}$ contained significantly greater fluorescent products than the unexposed samples. Values of $77.9 \pm 14.6,81.0 \pm 13.4$, and $23.3 \pm 11.1$, respectively, were obtained $(n=3)$.

Functional assays. In vitro surface tensions of samples incubated with $\mathrm{FeCl}_{2}+\mathrm{H}_{2} \mathrm{O}_{2}, \mathrm{FeCl}_{2}, \mathrm{H}_{2} \mathrm{O}_{2}$, or no additive were measured after $2 \mathrm{~h}$ of incubation and $10 \mathrm{~min}$ of bubble pulsation were $6.5 \pm 7.1,0.0 \pm 0.1,0.0 \pm 0.1$, and $0.0 \pm 0.0 \mathrm{mN} / \mathrm{m}$, respectively ( $n=12$, each group, Fig. 3). Function was diminished significantly for the sample exposed to the full oxidizing system $(P<0.0001)$. In vitro surface tensions after $10 \mathrm{~min}$ of bubble pulsation of samples exposed to $\mathrm{CuCl}_{2}$ for $24 \mathrm{~h}$, of samples incubated $24 \mathrm{~h}$ with no additive, of samples incubated 5

Table I. Fatty Acid Content as Percent of Total

\begin{tabular}{lllllllrr}
\hline \multicolumn{1}{c}{ Condition } & $14 / 0$ & $16 / 0$ & $16 / 1$ & $18 / 0$ & $18 / 1$ & $18 / 2$ & $20 / 4$ & Sat/unsat \\
\hline Control & 3.0 & 69.5 & 5.8 & 3.7 & 10.5 & 5.4 & 0.4 & 3.5 \\
$\mathrm{CuCl}_{2}$ & 4 & 71.2 & 6.3 & 3.6 & 10.2 & 3.8 & $<0.1$ & 3.9 \\
$\mathrm{FeCl}_{2}+\mathrm{H}_{2} \mathrm{O}_{2}$ & 4.1 & 74.9 & 5.6 & 4.0 & 9.7 & 1.3 & $<0.1$ & 5.0 \\
\hline
\end{tabular}

Samples were extracted with chloroform/methanol, washed, and dried. Fatty acid methyl esters were generated by treatment of the residue with sodium methoxide in methanol and detected by gas-liquid chromatography with flame ionization detection. Values represent avereages of at least two separate analyses per sample. Measurement variability within samples was $<3 \%$ and between duplicates was $\leq 10 \%$. 
min with $\mathrm{CuCl}_{2}$, or of unexposed unincubated surfactant samples after $10 \mathrm{~min}$ of bubble pulsation were $18.6 \pm 1.2,4.8 \pm 2.4$, $1.7 \pm 1.7$, and $1.4 \pm 1.4 \mathrm{mN} / \mathrm{m}$, respectively $(n=10,5,5$, and 5 ; Fig. 4). Function was diminished significantly for the sample exposed to $\mathrm{CuCl}_{2}$ for $24 \mathrm{~h}(P<0.00001)$.

In vivo function of surfactant was tested in the surfactantdeficient fetal rabbit. Compliance of the surfactant-deficient rabbit respiratory system was improved minimally at $60 \mathrm{~min}$ to $0.155 \pm 0.075 \mathrm{ml} / \mathrm{cmH}_{2} \mathrm{O}$ per $\mathrm{kg}(n=10)$ by administration of extracted pig surfactant that had been exposed to $\mathrm{FeCl}_{2}+\mathrm{H}_{2} \mathrm{O}_{2}$ (Fig. 5). In contrast, in animals receiving surfactant only, surfactant exposed to $\mathrm{H}_{2} \mathrm{O}_{2}$, or surfactant exposed to $\mathrm{FeCl}_{2}$, compliance improved significantly to $0.408 \pm 0.142,0.398 \pm 0.120$, or $0.327 \pm 0.167 \mathrm{ml} / \mathrm{cmH}_{2} \mathrm{O}$ per $\mathrm{kg}$, respectively $(n=9,9$, and $11 ; P<0.003$ ). Animals receiving surfactant that had been exposed to $\mathrm{CuCl}_{2}$ for $24 \mathrm{~h}$, surfactant exposed to $\mathrm{CuCl}_{2}$ for 5 min, unexposed surfactant, or no surfactant had compliances of $0.288 \pm 0.126,0.422 \pm 0.108,0.408 \pm 0.217$, and $0.085 \pm 0.027$, respectively $(n=8,8,10$, and 4$)$. The overall difference was significant $(0.04)$, but no post hoc comparisons were significant.

Having demonstrated that surfactant lipid peroxidation and loss of surface tension lowering function accompanied exposure of porcine surfactant (containing hydrophobic apoprotein) to oxidizing systems, experiments were performed with non-protein containing lipid mixtures to determine if exposure of lipids alone is sufficient to alter surface tension lowering function. Results of those experiments are presented in Table II and demonstrate that surfactants containing unsaturated phospholipids (e.g., POPG and DAPC) but not preparations containing only saturated phospholipid (e.g., Exosurf) lose surface tension lowering activity after exposure to oxidizing conditions. This loss is accompanied by generation of TBARS when the polyunsaturated lipid DAPC is present. We did not detect generation of nonsedimentable inhibitor from the DPPC/ POPG/PA/ \pm DAPG mixtures (Table II, preparation 4). Max-

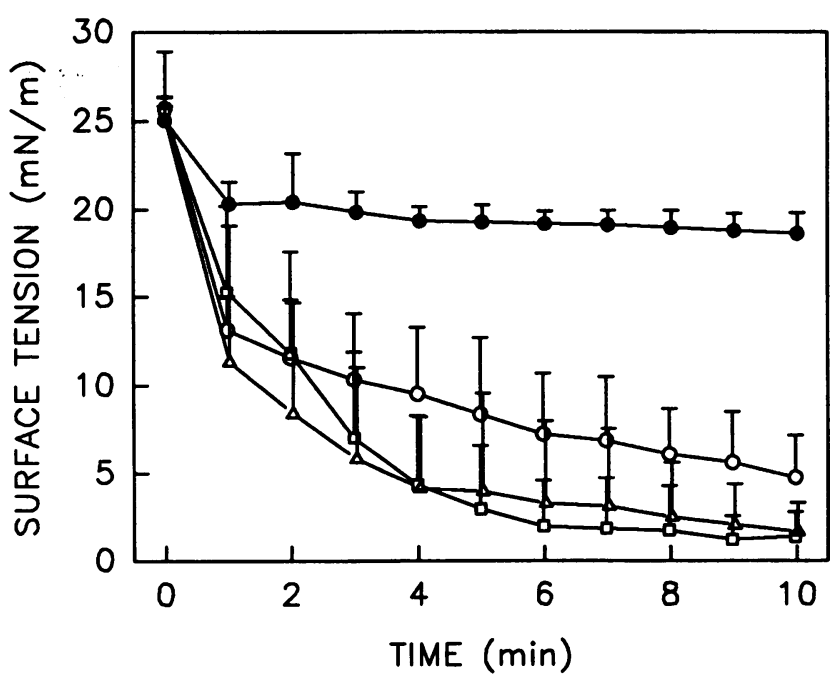

Figure 4. Bubble surfactometer surface tension measurements at minimum bubble size indicate significant inhibition of function of surfactant ( $1 \mathrm{mg} / \mathrm{ml}$ ) exposed to $5 \mu \mathrm{M} \mathrm{CuCl}_{2}$ for $24 \mathrm{~h} \mathrm{( \bullet )} \mathrm{compared}$ with surfactant exposed to $\mathrm{CuCl}_{2}$ for $5 \mathrm{~min}(\Delta)$, unexposed and incubated for $24 \mathrm{~h}(0)$, or unexposed and unincubated $(\square),(n=10$, 5, 5, and 5, respectively; mean \pm SEM; $P<0.00001$ ).

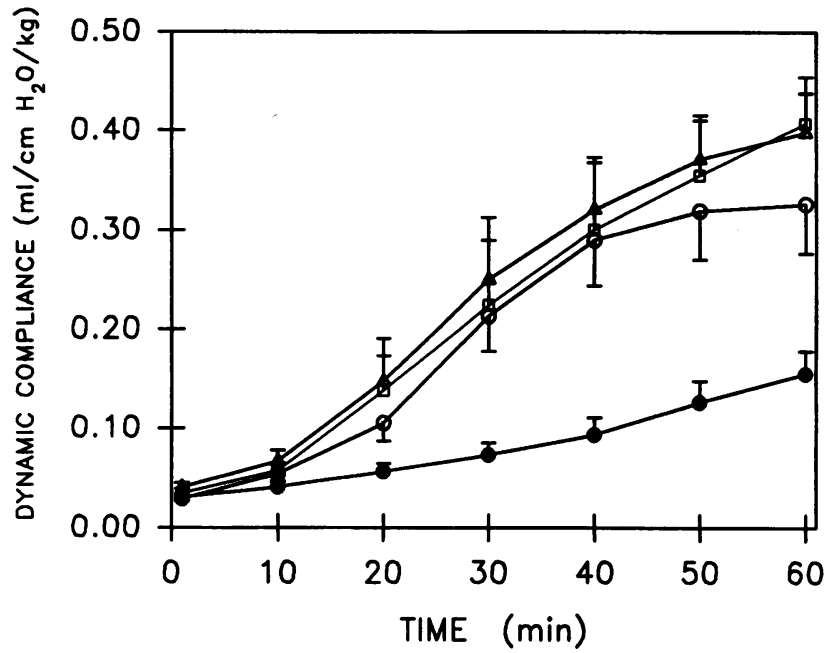

Figure 5. Surface tension assessment in vivo indicates significantly impaired ability of surfactant exposed to $\mathrm{Fe}+\mathrm{H}_{2} \mathrm{O}_{2}(\bullet)$ (conditions as for Fig. 2) to improve compliance of the surfactant-deficient fetal rabbit lung during $60 \mathrm{~min}$ of ventilation. In contrast, surfactant exposed to $\mathrm{FeCl}_{2}$ only $(\mathrm{O})$, to $\mathrm{H}_{2} \mathrm{O}_{2}$ only $(\Delta)$ or unexposed ( $\square$ ) exhibited ability to improve lung compliance, $(n=10,11,9$, and 9 , respectively; mean \pm SEM; $P<0.003$ ).

imum surface tension for all lipid mixtures was $55-67 \mathrm{mN} / \mathrm{m}$ and was not affected by oxidation. The centrifugation and resuspension required for these experiments did not affect the results.

\section{Discussion}

Because reactive oxygen products are released into the alveolar space during ARDS and because pulmonary surfactant function is altered in this syndrome, it is reasonable to speculate

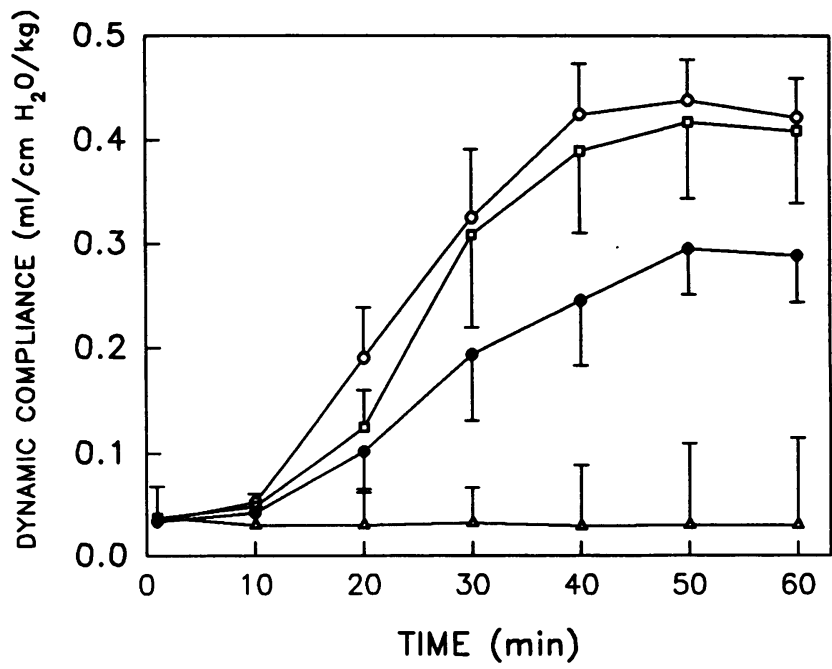

Figure 6. Surface tension assessment in vivo suggests impaired ability of surfactant exposed to $\mathrm{CuCl}_{2}$ for $24 \mathrm{~h}$ (•) (conditions as for Fig. 4 ) to improve compliance of the surfactant-deficient fetal rabbit lung. Surfactant exposed to $\mathrm{CuCl}_{2}$ for $5 \mathrm{~min}(\mathrm{O})$ and unexposed surfactant ( $\square$ ) were able to improve lung compliance, while animals receiving no treatment $(\Delta)$ showed little improvement in lung compliance $(n=8$, 8,10 , and 4 , respectively). 
Table II. Effect of Oxidant Exposure on Synthetic Surfactants

\begin{tabular}{|c|c|c|c|c|c|}
\hline Surfactant & Exposure & $n$ & Preparation & TBARS & Min ST \\
\hline & & & & & $m N / m$ \\
\hline \multirow[t]{3}{*}{ Mix } & None & 8 & 1 & 0.002 & $2.4 \pm 0.2$ \\
\hline & & 8 & 2 & & $1.6 \pm 0.5$ \\
\hline & & 6 & 3 & & $2.3 \pm 0.3$ \\
\hline \multirow[t]{3}{*}{ Mix } & $\mathrm{H}_{2} \mathrm{O}_{2}+\mathrm{FeCl}_{2}$ & 8 & 1 & 0.007 & $4.4 \pm 0.4$ \\
\hline & & 7 & 2 & & $3.8 \pm 0.3$ \\
\hline & & 6 & 3 & & $2.2 \pm 0.4$ \\
\hline \multirow[t]{4}{*}{ Mix + DAPC } & None & 10 & 1 & 0.026 & $2.8 \pm 0.2$ \\
\hline & & 10 & 2 & & $2.6 \pm 0.3$ \\
\hline & & 10 & 3 & & $1.9 \pm 0.4$ \\
\hline & & 6 & 4 & & $1.5 \pm 0.4$ \\
\hline \multirow[t]{3}{*}{ Mix + DAPC } & $\mathrm{H}_{2} \mathrm{O}_{2}+\mathrm{FeCl}_{2}$ & 10 & 1 & 0.405 & $6.5 \pm 0.8$ \\
\hline & & 10 & 2 & & $5.3 \pm 0.3$ \\
\hline & & 10 & 3 & & $4.12 \pm 0.5$ \\
\hline \multirow[t]{2}{*}{ Exosurf } & None & 4 & 2 & 0.009 & $0.9 \pm 0.4$ \\
\hline & & 2 & 3 & & $2.6 \pm 0.5$ \\
\hline \multirow[t]{2}{*}{ Exosurf } & $\mathrm{H}_{2} \mathrm{O}_{2}+\mathrm{FeCl}_{2}$ & 4 & & 0.009 & $0.5 \pm 0.0$ \\
\hline & & 2 & & & $1.2 \pm 0.2$ \\
\hline
\end{tabular}

Either a mixture (Mix) of DPPC, POPG, palmitic acid (3:1:0.6 wt/ $\mathrm{wt} / \mathrm{wt}$ in $50 \mathrm{mM} \mathrm{NaCl}$ ) with or without $2 \%$ (by weight) DAPC or Exosurf (DPPC, tyloxapol, hexadecanol, by weight 13.5:1.5:1) was oxidized by exposure to $0.2 \mathrm{mM} \mathrm{FeCl}_{2}+0.1 \mathrm{mM} \mathrm{H}_{2} \mathrm{O}_{2}$ as described and TBARS and minimum surface tension (Min ST) were determined. Surfactants were either analyzed directly (preparation $I$ ) or pelleted $(10,000 \mathrm{~g}$ for $60 \mathrm{~min})$ and resuspended in supernatant (preparation 2) or $150 \mathrm{mM} \mathrm{NaCl}, 5 \mathrm{mM} \mathrm{CaCl}_{2}, 5 \mathrm{mM}$ Tris (preparation 3). Unoxidized DPPC/POPG/PA/DAPC was resuspended in the supernatant of oxidized DPPC/POPG/PA/DAPC (preparation 4). Exosurf was adjusted to $0.125 \mathrm{mg} \mathrm{PL} / \mathrm{ml}$; other samples were adjusted to $1 \mathrm{mg} \mathrm{PL} / \mathrm{ml}$. Values are means \pm SE. Both in the presence and absence of DAPC, exposure to oxidant resulted in significant $(P<$ $0.001)$ loss of function. Function was slightly though significantly $(P$ $<0.001$ ) improved for samples prepared by method 1 vs method 3 (two-way ANOVA).

that the lipid components of pulmonary surfactant might be oxidized by these reactive oxygen products and that this oxidation might alter the surface tension lowering ability of surfactant.

Should such oxidation of surfactant lipid occur in vivo, one would expect to find evidence, however nonspecific, of lipid peroxidation products in lung tissue or lung lavage fluid. Such evidence has been presented by several investigators. Ward et al. (27) found that oxygen radical-mediated acute lung injury occurring after complement activation was closely associated with the appearance of lipid peroxidation products in plasma and in lung. Mohsenin documented an increase in lipid peroxidation products in the lipid extract of BAL from normal subjects after inhalation of $\mathrm{NO}_{2}$ for $3 \mathrm{~h}$ and also presented evidence of antiprotease activation consistent with oxidant generation (32). Thus, the presence of reactive oxygen products in the lung may be associated with the presence of lipid peroxidation products. However, because phospholipids are ubiquitous components of cell membranes and because cellular debris is always present in BAL of patients with acute lung injury, it is not possible to identify the source of lung or BAL lipid peroxidation products. Thus, we have relied on in vitro observations.

Pulmonary surfactant phospholipids contain few polyunsat- urated fatty acid side chains ( $\sim 1.5 \%$ of the total) $(33)$ and thus should be relatively resistant to peroxidation. Moreover, surfactant is produced in an environment rich in antioxidants, chiefly catalase and to a lesser extent superoxide dismutase and glutathione (34). Nevertheless, two factors may promote oxidation of surfactant lipids in the lungs of patients with acute lung inflammation. First, antioxidant defenses may be exhausted by an excess of reactive oxygen products and may fail to provide protection. Second, the major antioxidant species in the alveolus may be excluded from the microenvironment in which lipid peroxidation occurs. Neutrophil superoxide production occurs on the surface of the lipid bilayer, and close approximation of this bilayer to surfactant lipids may occur in an environment that functionally excludes the hydrophilic proteins that provide the major antioxidant defense of the lower airway.

Possible deleterious effects of reactive oxygen species on pulmonary surfactant have been addressed previously by Seeger et al. (35). They incubated unpurified rabbit lung lavage fluid that contained surfactant with oxygen radical-generating systems and measured functional alterations using the Wilhelmy balance. A common profile of changes was found, including delayed reduction of surface tension during compression with an increase in minimal compressibility, accelerated decrease of film pressure during expansion, reduction of hysteresis area, and augmented monolayer collapse rate. Minimum surface tension was not affected. Findings were present even when TBARS or organic hydroperoxides could not be detected.

In contrast, our results show that exposure of hydrophobic surfactant components to copper or $\mathrm{FeCl}_{2} / \mathrm{H}_{2} \mathrm{O}_{2}$ resulted in production of lipid peroxidation products associated with loss of surface tension lowering ability. We used two oxidizing systems of markedly different oxidizing capability. Esterbauer (24) described the use of $\mathrm{CuCl}_{2}$ to induce oxidative modification of LDL as process of lipid peroxidation "in which the polyunsaturated fatty acids of LDL are successively degraded to a variety of products." This process may also be accompanied by hydrolysis of phosphatidylcholine at the 2-position converting PC to lysoPC by an apparent phospholipase $\mathrm{A}_{2}$ activity (36).

Incubation of the hydrophobic components of pig pulmonary surfactant with these two oxidant-generating systems was associated with the production of a variety of lipid peroxidation products. The increase in $\mathrm{A}_{234}$ over time can be interpreted as the accumulation of lipid hydroperoxides. These compounds are the primary products of lipid peroxidation and they have a maximum absorption of approximately $234 \mathrm{~nm}$, coinciding with our experimental findings (Fig. 1, $A$ and $B$ ). The rate and degree of lipid peroxidation is most frequently measured with the TBA assay, which measures the amount of malondialdehyde-like substance formed by the peroxidation process. This assay is sensitive but relatively nonspecific (37). Production of malondialdehyde from phospholipids requires the presence of polyunsaturated side chains (37). We calculate that $1 \mathrm{mg}$ surfactant PL should allow production of up to $\sim 42$ nmol MDA. Thus, while positive results can occur in the presence of carbohydrates and amino acids (38), our results do not exceed the theoretical limits of MDA available from phospholipid peroxidation.

Other observations, including the increases in hydroxy alkenal content and fluorescent products and loss of unsaturated 
fatty acids are consistent with lipid peroxidation. As reviewed elsewhere, fluorescent products of lipid peroxidation are produced during in vitro oxidation of phospholipids under a variety of circumstances. Fluorescence may be due to production of conjugated Schiff bases and may be found in extracts of cells and tissues exposed to oxidizing conditions (27).

The oxidizing conditions to which we exposed surfactant produced relatively different effects. Exposure to $\mathrm{FeCl}_{2} / \mathrm{H}_{2} \mathrm{O}_{2}$ resulted in greater production of conjugated dienes, TBARS, $\mathrm{HNE}, \mathrm{HOE}$, and greater loss of unsaturated fatty acids than did exposure to $\mathrm{CuCl}_{2}$. In vivo functional effects paralleled these changes, with the greater impairment of function associated with exposure of surfactant to $\mathrm{FeCl}_{2} / \mathrm{H}_{2} \mathrm{O}_{2}$.

While both disruption of surfactant hydrophobic apoproteins and formation of lysophosphatidylcholine might contribute to loss of surfactant function associated with exposure to reactive oxygen species, experiments reported here suggest that peroxidation of non-protein containing surface-active lipid mixtures that contain unsaturated acyl groups results in detectable loss of surface tension lowering function. As nonsedimentable inhibitors were not detected, loss of function may be due to generation of phospholipid aldehydes that react with surfactant lipids to disrupt the surfactant monolayer at the air-fluid interface. It is not yet shown that oxidized lipid mixtures such as we have prepared have altered function in vivo. Experiments to explore that question may involve recombination of such altered lipids with surfactant apoproteins and investigation of the function in vivo of such protein-containing mixtures.

The changes in minimum surface tension of natural or synthetic surfactant that resulted from exposure to the oxidant system, while statistically significant, are modest and range from 2 to $6 \mathrm{mN} / \mathrm{m}$. Whether these changes are sufficient to explain the loss of function observed in in vivo remains to be determined. Although poor in vitro function is often predictive of poor in vivo function, good in vitro function does not necessarily predict similar function in vivo.

When lipid peroxidation occurs in the presence of SP-B or other critical peptides, the reactive lipid products such as MDA that are generated may form stable adducts with those molecules. Such reactions have been described with very low density lipoprotein (VLDL) apoproteins (39), and a similar event involving critical hydrophobic surfactant apoproteins may result in inhibition of surfactant function.

Our experimental findings should be viewed with several reservations. First, we have investigated the effects of oxidation in a system containing only the hydrophobic components of lung surfactant. These are precisely the components used to supplement surfactant in lungs of patients with infant or ARDS (10, 40-42). The surfactant glycoapoprotein SP-A, any contaminating proteins present in bronchoalveolar lavage, and hydrophobic antioxidants were absent from the material we examined; it will be important to understand how their presence might affect surfactant oxidation. Second, ionic strength or osmolarity of oxidant-treated porcine surfactant may have differed from that of control, resulting in a change of dynamic surface tension. Experiments with synthetic surfactants argue against this possibility, as oxidant-treated mixtures that were pelleted and resuspended in buffer of defined composition exhibited surface tension properties similar to that of unsedimented surfactant.

Recently, Holm et al. (43) have reported a dose-dependent inhibitory effect of lysoPC on the surface tension activity of calf lung surfactant extract tested in a surfactometer. However, we effectively removed soluble peroxidation products from surfactant by centrifugation and resuspension before in vivo testing of function, and thus lysoPC is unlikely to be responsible for the inhibition of surfactant function that we observed.

In summary, results of these experiments demonstrate a significant loss of surface tension lowering ability of the hydrophobic components of porcine lung surfactant and of a protein-free synthetic lipid mixture after exposure of these preparations to oxidizing conditions. Lipid peroxidation occurred in association with loss in function of porcine surfactant. The oxidizing conditions used reflect aspects of the environment present at the surface of the activated phagocyte in the alveolar space. Recently, Ryan et al. (44) have demonstrated loss of function of surfactant exposed to activated PMNs. Oxidation of surfactant components may be one mechanism contributing to this loss of function.

\section{Acknowledgments}

This work was supported by grant HL-23584 from the National Institutes of Health and grant 3RT-0151 from the University of California Tobacco Related Disease Research Program.

\section{References}

1. King, R. J. 1982. Pulmonary surfactant. J. Appl. Physiol. 53:1-8.

2. Ashbaugh, D. G., D. B. Bigelow, T. L. Petty, and B. E. Levine. 1967. Acute respiratory distress in adults. Lancet. 2:319-323.

3. Hallman, M., R. G. Spragg, J. H. Harrell, K. M. Moser, and L. Gluck. 1982. Evidence of lung surfactant abnormality in respiratory failure: study of bronchoalveolar lavage phospholipids, surface activity, phospholipase activity, and plasma myoinositol. J. Clin. Invest. 70:673-683.

4. Pison, U., W. Seeger, R. Buchhorn, T. Joka, M. Brand, U. Obertacke, H. Neuhof, and K. P. Schmit-Neuerburg. 1989. Surfactant abnormalities in patients with respiratory failure after multiple trauma. Am. Rev. Respir. Dis. 140:10331039.

5. Gregory, T. J., W. J. Longmore, M. A. Moxley, J. A. Whitsett, C. R. Reed, A. A. Fowler III, L. D. Hudson, R. J. Maunder, C. Crim, and T. M. Hyers. 1991. Surfactant chemical composition and biophysical activity in acute respiratory distress syndrome. J. Clin. Invest. 88:1976-1981.

6. Liau, D. F., C. R. Barrett, A. L. Bell, and S. F. Ryan. 1987. Functional abnormalities of lung surfactant in experimental acute alveolar injury in the dog. Am. Rev. Respir. Dis. 136:395-401.

7. Holm, B. A., R. H. Notter, J. Siegle, and S. Matalon. 1985. Pulmonary physiological and surfactant changes during injury and recovery from hyperoxia. J. Appl. Physiol. 59:1402-1409.

8. Engstrom, P. C., B. A. Holm, and S. Matalon. 1989. Surfactant replacement attenuates the increase in alveolar permeability in hyperoxia. J. Appl. Physiol. 67:688-693.

9. Berggren, P., B. Lachmann, T. Curstedt, G. Grossmann, and B. Robertson. 1986. Gas exchange and lung morphology after surfactant replacement in experimental adult respiratory distress syndrome induced by repeated lung lavage. Acta Anaesthesiol. Scand. 30:321-328.

10. Richman, P. S., R. G. Spragg, B. Robertson, T. A. Merritt, and T. Curstedt. 1989. The adult respiratory distress syndrome: first trials with surfactant replacement. Eur. J. Respir. Dis. Suppl. 3:109s-111s.

11. Lachmann, B. 1989. Animal models and clinical pilot studies of surfactant replacement in adult respiratory distress syndrome. Eur. Respir. J. 2(Suppl. 3): $98 \mathrm{~s}-103 \mathrm{~s}$.

12. Schlag, G., W.-H. Voigt, G. Schnells, and A. Glatzl. 1977. Vergleichende Untersuchungen der Ultrastrucktur von menschlicher Lunge und Skeletmuskulatur im Schock. II. Anaesthesist. 26:612-622.

13. Bachofen, M., and E. R. Weibel. 1977. Alterations of the gas exchange apparatus in adult respiratory insufficiency associated with septicemia. Am. Rev. Respir. Dis. 116:589-615.

14. Lee, C. T., A. M. Fein, M. Lippman, H. Holtzmann, P. Kimbel, and G. Wienbaum. 1981. Elastolytic activity in pulmonary lavage fluid from patients with adult respiratory distress syndrome. $N$. Engl. J. Med. 304:192-196.

15. McGuire, W. W., R. G. Spragg, A. B. Cohen, and C. G. Cochrane. 1982. Studies on the pathogenesis of the adult respiratory distress syndrome. J. Clin. Invest. 69:543-553.

16. Wewers, M. D., D. J. Herzyk, and J. E. Gadek. 1988. Alveolar fluid neutrophil elastase activity in the adult respiratory distress syndrome is complexed to alpha-2-macroglobulin. J. Clin. Invest. 82:1260-1267. 
17. Spragg, R. G., N. Gilliard, P. Richman, R. M. Smith, R. D. Hite, D. Pappert, B. Robertson, T. Curstedt, and D. Strayer. 1994. Acute effects of a single dose of porcine surfactant on patients with the adult respiratory distress syndrome. Chest. 105:195-202.

18. Cochrane, C. G., R. G. Spragg, S. D. Revak, A. B. Cohen, and W. W. McGuire. 1983. The presence of neutrophil elastase and evidence of oxidation activity in bronchoalveolar lavage fluid of patients with adult respiratory distress syndrome. Am. Rev. Respir. Dis. 127:S25-S27.

19. Baldwin, S. B., R. H. Simon, C. M. Grum, L. H. Ketai, L. A. Boxer, and L. J. Devall. 1986. Oxidant activity in the expired breath of patients with adult respiratory distress syndrome. Lancet. 1:11-14.

20. Weiss, S. J. 1989. Tissue destruction by neutrophils. N. Engl. J. Med. 320:365-376

21. Esterbauer, H. 1985. Lipid peroxidation products: formation, chemical properties and biological activities. In Free Radicals in Liver Injury. G. Poli, K. H. Cheeseman, M. U. Dianzani, and T. F. Slater, editors. IRL Press Limited, Oxford. 29-47.

22. Bligh, E. G., and W. J. Dyer. 1959. A rapid method of total lipid extraction and purification. Can. J. Biochem. Physiol. 37:911-917.

23. Rouser, G., S. Fleischer, and A. Yamamoto. 1970. Two dimensional thin layer chromatographic separation of polar lipids and determination of phospholipids by phosphorus analysis of spots. Lipids. 5:494-496.

24. Esterbauer, H., G. Striegl, H. Puhl, and M. Rotheneder. 1989. Continuous monitoring of in vitro oxidation of human low density lipoprotein. Free Radical Res. Commun. 6:67-75.

25. Minotti, G., and S. D. Aust. 1987. The requirement for the iron(III) in the initiation of lipid peroxidation by iron(II) and hydrogen peroxide. J. Biol. Chem. 262:1098-1104

26. Lunec, J., S. P. Halloran, A. G. White, and T. L. Dormandy. 1981. Freeradical oxidation (peroxidation) products in serum and synovial fluid in rheumatoid arthritis. J. Rheumatol. 8:233-245.

27. Ward, P. A., G. O. Till, J. R. Hatherill, T. M. Annesley, and R. G. Kunkel. 1985. Systemic complement activation, lung injury, and products of lipid peroxidation. J. Clin. Invest. 76:517-527.

28. Esterbauer, H., K. H. Cheeseman, M. U. Dianzani, G. Poli, and T. F. Slater. 1982. Separation and characterization of the aldehydic products of lipid peroxidation stimulated by $\mathrm{ADP}-\mathrm{Fe}^{2+}$ in rat liver microsomes. Biochem. $J$. 208:129-140.

29. Biesalski, H., H. Greiff, K. Brodda, G. Hafner, and K. H. Bassler. 1986. Rapid determination of vitamin $\mathrm{A}$ ( retinol) and vitamin $\mathrm{E}$ (alpha-tocopherol) in human serum by isocratic adsorption HPLC. Int. J. Vitam. Nutr. Res. 56:319327.

30. Sedlak, J., and R. H. Lindsay. 1968. Estimation of total, protein-bound, and nonprotein sulfhydryl groups in tissue with Ellman's reagent. Anal. Biochem. 25:192-205.

31. Enhorning, G. 1977. A pulsating bubble technique for evaluating pulmonary surfactant. J. Appl. Physiol. 43:198-201.

32. Mohsenin, V. 1991. Lipid peroxidation and antielastase activity in the lung under oxidant stress: role of antioxidant defenses. J. Appl. Physiol. 70:14561462.

33. Yu, S., G. R. Harding, M. Smith, and F. Possmayer. 1983. Bovine pulmonary surfactant: chemical composition and physical properties. Lipids. 18:522529.

34. Cantin, A. M., G. A. Fells, R. C. Hubbard, and R. G. Crystal. 1990. Antioxidant macromolecules in the epithelial lining fluid of the normal human lower respiratory tract. J. Clin. Invest. 86:962-971.

35. Seeger, W., H. Lepper, R. D. Hellmut, and H. Neuhof. 1985. Alteration of alveolar surfactant function after exposure to oxidative stress and to oxygenated and native arachidonic acid in vitro. Biochim. Biophys. Acta. 835:58-67.

36. Steinbrecher, U. P., S. Parthasarathy, D. S. Leake, J. L. Witztum, and D. Steinberg. 1984. Modification of low density lipoprotein by endothelial cells involves lipid peroxidation and degradation of low density lipoprotein phospholipids. Proc. Natl. Acad. Sci. USA. 81:3883-3887.

37. Dahle, L. K., E. G. Hill, and R. T. Holman. 1962. The thiobarbituric acid reaction and the autoxidations of polyunsaturated fatty acid methyl esters. Arch. Biochem. Biophys. 98:253-261.

38. Gutteridge, J. M. C. 1981. Thiobarbituric acid-reactivity following irondependent free-radical damage to amino acids and carbohydrates. FEBS (Fed. Eur. Biochem. Soc.) Lett. 128:343-346.

39. Palinski, W., S. Yla-Herttuala, M. E. Rosenfeld, S. W. Butler, S. A. Socher, S. Parthasarathy, L. K. Curtiss, and J. L. Witztum. 1990. Antisera and monoclonal antibodies specific for epitopes generated during oxidative modification of low density lipoprotein. Arteriosclerosis. 10:325-335.

40. Fujiwara, T., S. Chida, Y. Watabe, H. Maeta, T. Morita, and T. Abe. 1980. Artificial surfactant therapy in hyaline-membrane disease. Lancet. i:55-59.

41. Robertson, B. 1990. European multicenter trials of Curosurf for treatment of neonatal respiratory distress syndrome. Lung. 168(Suppl.):860-863.

42. Kendig, J. W., R. H. Notter, and C. Cox. 1988. Surfactant replacement therapy at birth: final analysis of a clinical trial and comparisons with similar trials. Pediatrics. 82:756-762.

43. Holm, B. A., L. Keicher, M. Y. Liu, J. Sokolowski, and G. Enhorning 1991. Inhibition of pulmonary surfactant function by phospholipases. J. Appl. Physiol. 71:317-321.

44. Ryan, S. F., Y. Ghassibi, and D. F. Liau. 1991. Effects of activated polymorphonuclear leukocytes upon pulmonary surfactant in vitro. Am. J. Respir Cell Mol. Biol. 4:33-41. 